\title{
Thrombocytosis and ischaemic complications in giant cell arteritis
}

\author{
Jacques De Keyser, Nina De Klippel, \\ Guy Ebinger
}

Department of Neurology, Academisch Ziekenhuis, Vrije Universiteit Brussel, B 1090 Brussels, Belgium Jacques De Keyser, PHD, neurologist

Nina De Klippel, MD, assistant

Guy Ebinger, PHD, head of department

Correspondence to:

Dr De Keyser.

$B M J 1991 ; 303: 825$
Platelet counts may be raised in giant cell arteritis ${ }^{2}$ but the clinical relevance of this has not been examined. We have investigated the possibility of an association between thrombocytosis and ocular or cerebral ischaemic events in giant cell arteritis.

\section{Patients, methods, and results}

We reviewed the medical records of patients with a diagnosis of giant cell arteritis who were admitted to the University Hospital of the Vrije Universiteit Brussel between 1984 and 1989. The diagnosis was based on clinical features, laboratory data (raised erythrocyte sedimentation rate), biopsy findings in temporal arteries, good response to corticosteroid treatment, and subsequent course. The study population consisted of 56 patients ( 31 women, 25 men) aged 60-89 years (mean 75.6 (SD 6.3)). Platelet count was determined as routine with an automated counter (normal range $150-400 \times 10^{9} / 1$ ) before corticosteroid treatment.

Patients were assigned to one of two groups based on the presence or absence of transient or permanent visual loss, transient cerebral ischaemic attack, or stroke. Age and sex distributions of the groups were similar (table). Eighteen patients (32\%) had a history of ischaemic complications. Transient or permanent visual loss occurred in 13, transient cerebral ischaemic attacks in seven (all in the vertebrobasilar system), and stroke in two (one patient died from a brain stem infarction and the other had an infarction in the territory of the middle cerebral artery).

In the whole study population thrombocytosis

Findings in 56 patients with giant cell arteritis

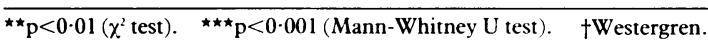

(platelet count $>400 \times 10^{9} / 1$ ) was found in 21 patients $(37 \cdot 5 \%)$. Linear regression analysis showed no correlation between platelet count and erythrocyte sedimentation rate $(r=0.06)$ or haemoglobin concentration $(r=0 \cdot 15)$. There was no relation between thrombocytosis and positive biopsy findings in temporal arteries. In 13 patients with thrombocytosis platelet counts were remeasured two to three weeks after corticosteroid treatment had been started; values had returned to normal in all.

The group with ischaemic complications had a significantly higher prevalence of thrombocytosis $(\mathrm{p}<0.01)$ and a higher median platelet count $(\mathrm{p}<0.001)$ than the group without ischaemic complications (table).

\section{Comment}

Thrombocytosis in giant cell arteritis results from an increased production of platelets. ${ }^{2}$ Our results show an assuciation between thrombocytosis and the occurrence of ocular and cerebral ischaemic complications in giant cell arteritis.

Reactive thrombocytosis has been detected in various other inflammatory diseases, such as rheumatoid arthritis, ankylosing spondylitis, and inflammatory bowel disease. ${ }^{3}$ The exact underlying mechanism responsible for the increase in platelet production is unknown. A first possible explanation for our findings is that thrombocytosis in giant cell arteritis reflects a more severe degree of vasculitis. We found no correlation between platelet count and erythrocyte sedimentation rate.

A second possibility is that thrombocytosis might contribute to the ischaemic complications in giant cell arteritis. However, there have been no convincing reports that ischaemic manifestations occur as a direct consequence of reactive thrombocytosis in other disorders, at least not with the rather moderate increases in platelet count detected in our patients. The lumen of arteries affected by giant cell arteritis is usually reduced by severe thickening of the intima, and thrombosis is often found at the site of active inflammation. ${ }^{1245}$ Hence we cannot exclude the possibility that in some patients with giant cell arteritis thrombocytosis may be pathologically significant in narrowed inflamed arteries.

1 Calamia KT, Hunder GG. Clinical manifestations of giant-cell (temporal) arteritis. Clin Rheum Dis 1980;6:389-403.

2 Bengtsson B-A, Malmvall B-E. Giant cell arteritis. Acta Med Scand 1982;suppl No 658:1-102.

3 Selroos O. Thrombocytosis. Acta Med Scand 1973;193:431-6.

4 Goodman B. Temporal arteritis. Am f Med 1979;67:839-52.

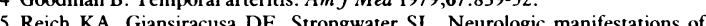
giant-cell arteritis. Am F Med 1990;89:67-72.

(Accepted 11 June 1991)

\section{Secretor status and heterosexual transmission of HIV}

\author{
C C Blackwell, V S James, S Davidson, R Wyld, \\ R P Brettle, R J Robertson, D M Weir
}

\begin{abstract}
Correspondence to:
\end{abstract} Dr Blackwell.

$B M \mathcal{F} 1991 ; 303: 825-6$
In contrast to previous studies on bacterial diseases and superficial fungal infections, in which non-secretors of the $\mathrm{ABO}$ blood group antigens were significantly overrepresented,,$^{12}$ we found a higher proportion of secretors among patients with some viral illnesses. ${ }^{3}$ Previously, we predicted that among patients who acquired HIV through intravenous drug use or anal intercourse the proportions of secretors and nonsecretors would reflect that of the local population as these routes of transmission bypass normal mucosal defences. ${ }^{2}$

We examined the hypothesis that among subjects exposed to HIV through heterosexual activities a significantly higher proportion of secretors would become infected with the virus.

\section{Subjects, methods, and results}

We studied 219 subjects: 151 (99 men and 52 women) who acquired HIV through drug use; 14 homosexual or bisexual men; and 54 (15 men and 39 women) whose only risk factor when they entered the study was heterosexual intercourse with a partner infected with HIV. 